\title{
Born from pre-eclamptic pregnancies predisposes infants to altered cortisol metabolism in the first postnatal year
}

\author{
Fiona Broughton Pipkin 1,*, Hiten D Mistry 2,*, Chandrima Roy³, Bernhard Dick ${ }^{2}$, \\ Jason Waugh ${ }^{3}$, Rebecca Chikhi ${ }^{2}$, Lesia 0 Kurlak ${ }^{1}$ and Markus G Mohaupt ${ }^{2}$ \\ ${ }^{1}$ Department of Obstetrics and Gynaecology, School of Medicine, University of Nottingham, Nottingham, \\ NG5 1PB, UK \\ ${ }^{2}$ Department of Nephrology, Hypertension and Clinical Pharmacology, Clinical Research, University of Bern, \\ 3010 Berne, Switzerland \\ ${ }^{3}$ Leicester Royal Infirmary, Leicester, LE1 5WW, UK \\ ${ }^{*}$ (F Broughton Pipkin and H D Mistry contributed equally to this work)
}

Correspondence

should be addressed

to M G Mohaupt

Email

markus.mohaupt@insel.ch

\begin{abstract}
Pre-eclampsia leads to disturbed fetal organ development, including metabolic syndrome, attributed to altered pituitary-adrenal feedback loop. We measured cortisol metabolites in infants born from pre-eclamptic and normotensive women and hypothesised that glucocorticoid exposure would be exaggerated in the former. Twenty-four hour urine was collected from infants at months 3 and 12. Cortisol metabolites and apparent enzyme activities were analysed by gas chromatography-mass spectrometry. From 3 to 12 months, excretion of THS, THF and pregnandiol had risen in both groups; THF also rose in the pre-eclamptic group. No difference was observed with respect to timing of the visit or to hypertensive status for THE or total $\mathrm{F}$ metabolites $(P>0.05)$. All apparent enzymes activities, except $17 \alpha$-hydroxylase, were lower in infants at 12 compared to 3 months in the normotensive group. In the pre-eclamptic group, only $11 \beta$-HSD activities were lower at 12 months. $17 \alpha$-hydroxylase and $11 \beta$-HSD activities of tetrahydro metabolites were higher in the pre-eclamptic group at 3 months $(P<0.05)$. 11 $\beta$-hydroxylase activity increased in the pre-eclamptic group at 12 months. Cortisol excretion, determined by increased $11 \beta$-hydroxylase, compensates for high $11 \beta$-HSD-dependent cortisol degradation at 3 months and at 12 months counterbalances the reduced cortisol substrate availability in infants born from pre-eclamptic mothers.
\end{abstract}

\section{Key Words}

- steroid hormones

- pre-eclampsia

- infants

- urine

\section{Introduction}

The fetal adrenal gland and hypothalamic-pituitary axis (HPA) play important roles during pregnancy. Between weeks 32 and 34 of gestation, there is a rapid maturation of the fetal adrenal cortex, allowing development of a variety of mechanisms associated with a successful transition to extrauterine life $(1,2,3,4)$. Frequently, intrauterine
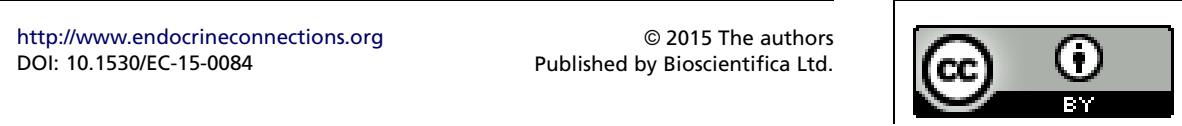
growth restriction (IUGR) and premature delivery are due to pre-eclampsia (5), a pregnancy-specific syndrome occurring in $\sim 3 \%$ of all pregnancies and one of the leading causes of maternal/perinatal mortality and morbidity worldwide $(6,7)$. Various organ functions in these infants are subject to intrauterine developmental reprogramming $(8,9)$, with evidence of decreased pituitary adrenal feedback control of glucocorticoid maintenance and an association with metabolic syndrome $(10,11)$.

Little is known about steroid hormone availability and metabolism during the early postpartum period in infants. Fetal exposure to maternal cortisol is low, as it is tightly regulated by the placental enzyme $11 \beta$-hydroxysteroiddehydrogenase type 2 (11ß-HSD), assumed to protect the fetus against high active levels of glucocorticoids. Enhanced maternal 'stress', reduced placental cortisol inactivation due to mechanisms such as a compromised placental $11 \beta$-HSD activity in pre-eclampsia (12) and/or a hypoxic fetal environment, might lead to increased fetal exposure to cortisol in pregnancy and during birth $(13,14,15)$. Fetal exposure to exogenous glucocorticoids, to enhance lung maturation, is a further confounder for fetal cortisol exposure (16). The premature infant must counterbalance the hormonal demands of acute critical stress against those of growth and organ maturation (17). Corticotrophin-releasing hormone (CRH) challenge tests in premature infants have demonstrated that the ability of the pituitary to respond adequately to $\mathrm{CRH}$ stimulation depends not only on the dose of $\mathrm{CRH}$, but also on the maturity of the pituitary-adrenal axis $(18,19)$. Two types of response are conceivable: First, adrenal cortical responsiveness could be downregulated at birth due to the relatively high prenatal glucocorticoid exposure. Second, given compromised intrauterine development, the adaptation to later life requirements for steroid hormone production could be enhanced by an already dysfunctional central feedback response. As adrenal and central nervous perfusion is maintained even during fetal distress, any change might be subtle and only apparent when a need for sensitive regulation arises.

Though potentially biased by the fact that nonsurviving fetuses cannot be evaluated, we hypothesised that glucocorticoid exposure is exaggerated after preeclampsia. We aimed to investigate cortisol metabolism (Fig. 1), at postnatal months 3 and 12 in infants born to pre-eclamptic and normotensive mothers.

Previous studies have used immunoassays which have the problem of steroid cross reactivity $(20,21)$. We have addressed this problem by utilising gas chromatographymass spectrometry (GC-MS) (22). In addition, we have measured steroids in $24 \mathrm{~h}$ urine collections, which enables a non-invasive assessment of hormonal production rates

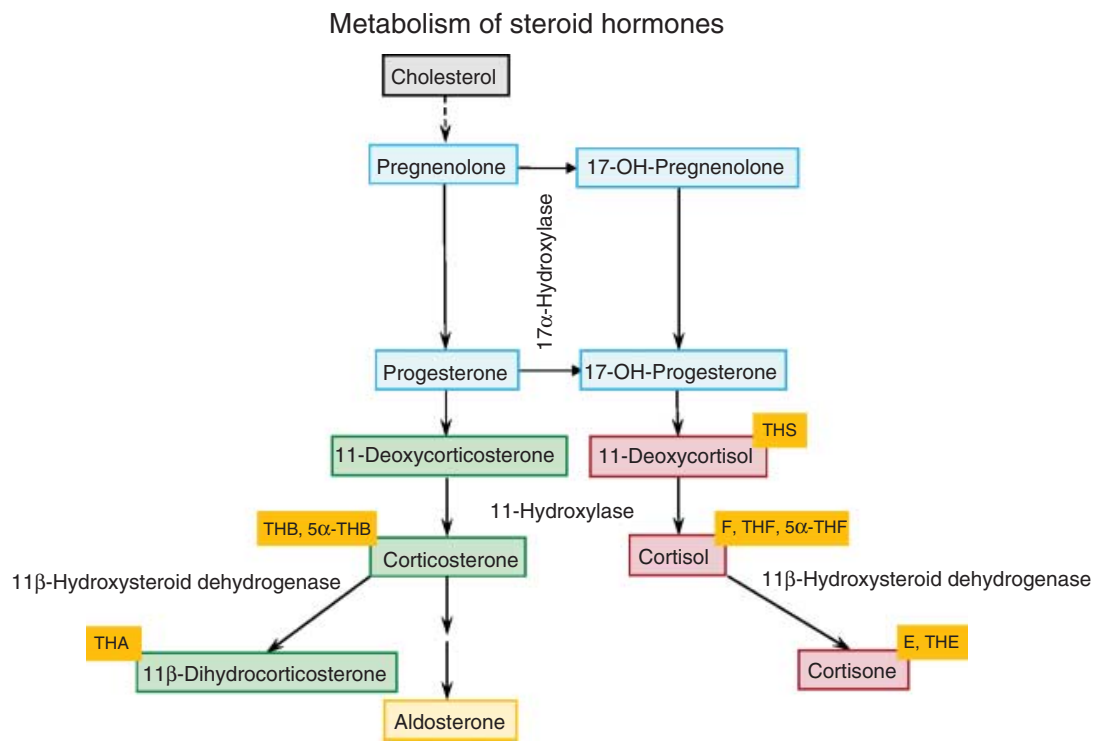

\section{Figure 1}

Schematic flow diagram representing the steroid hormone pathways regulating cortisol availability. Progesterone-, corticosterone- and cortisolrelated steroid hormones are labelled blue, green and red respectively.
Steroid hormone metabolites used to assess a given steroid hormone are shown in yellow boxes. Enzymes, whose apparent activities have been calculated within the manuscript, are marked.

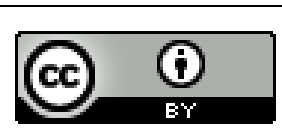

This work is licensed under a Creative Commons Attribution 3.0 Unported License. 
and reflects approximately $70 \%$ of the cortisol production rate in adults, as determined by stabilised isotope dilution technique (23).

\section{Material and methods}

\section{Subjects}

This study was performed as part of a considerably larger study comparing infants born to pre-eclamptic and suitably matched normotensive pregnancies with the aim of 100 in each group. Although a majority of these women initially agreed to collect nappies, a number of these dropped out at 3 months and even more so at 12 months, leaving final group sizes of normotensive (3 months: $n=50 ; 12$ months: $n=29$ ) and pre-eclamptic (3 months: $n=45 ; 12$ months: $n=16$ ) pregnancies. Infants of pre-eclamptic mothers were matched to normotensive controls by \pm 1 week of gestation age at delivery.

In this cross-sectional study, all parents of the participants, who were recruited from Leicester Royal Infirmary Teaching Hospital, gave informed, written consent to participation on behalf of their infants. The protocol was approved by the Trent Multicentre Research Ethics Committee. Infants born from a pre-eclamptic pregnancy and closely matched (see the previous discussion) infants born to normotensive pregnancies were eligible for the study. Pre-eclampsia was stringently defined using the International Society for the Study of Hypertension in Pregnancy guidelines of systolic blood pressure of $140 \mathrm{~mm} \mathrm{Hg}$ or more and diastolic pressure (Korotkoff $\mathrm{V}$ ) of $90 \mathrm{~mm} \mathrm{Hg}$ or more on two occasions after 20 weeks gestation in a previously normotensive woman, together with proteinuria of $\geq 300 \mathrm{mg} / \mathrm{l}, \geq 500 \mathrm{mg} /$ day or $\geq 2+$ on dipstick analysis of midstream urine (MSU) if 24 -h collection result was not possible (24). Infants with low birth weight due to congenital infections such as cytomegalovirus, dysmorphism, twins, severe cerebral palsy, congenital heart disease, acute infections, hyaline membrane disease or other respiratory disease, jaundice, hypoglycaemia or with a history of urinary tract infections, urological or renal problems were excluded. Demographic data for the children were recovered from the hospital records and are presented in Table 1.

Table 1 Pregnancy and infant demographic and outcome data for these unpaired cross-sectional samples at 3 and 12 months ${ }^{a}$.

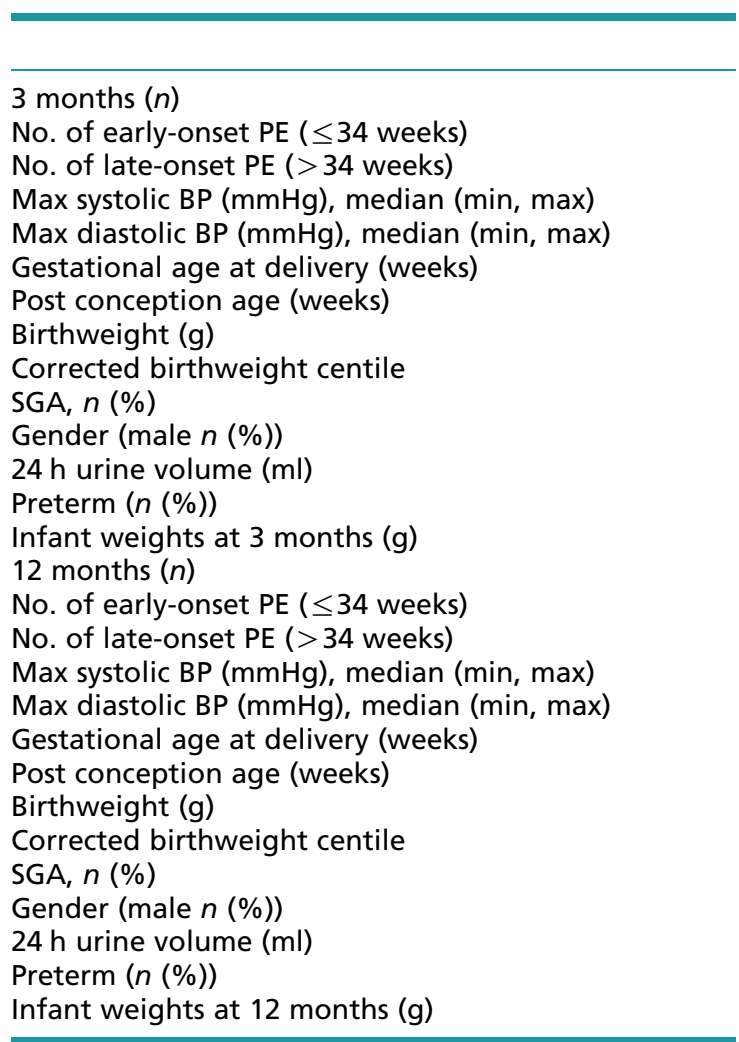

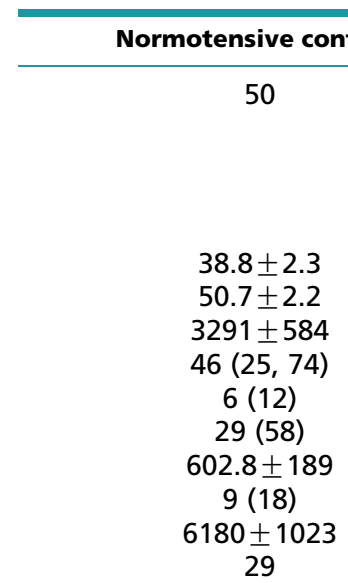

$* P<0.05$.

${ }^{\mathrm{a}}$ Data presented as either mean \pm s.D. or median (IQR).
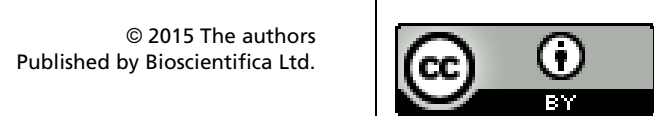

This work is licensed under a Creative Commons Attribution 3.0 Unported License. 
The corrected birthweight percentile for each infant was computed, correcting for gestational age at delivery, gender, maternal parity, and BMI (25).

\section{Urinary sampling}

Urine was collected at postnatal months 3 and 12 months, over $24 \mathrm{~h}$ using pure cellulose disposable nappies provided in advance to the mothers. A thin gauze was placed between the baby's skin and the surface of the inner side of the nappy to reduce contamination with meconium or stool (26); samples with diarrhoea were omitted. Nappies of the appropriate size were changed every $4 \mathrm{~h}$ for term and $8 \mathrm{~h}$ for preterm infants and were weighed before and after urine collections, allowing exact calculation of 24-h urine output (27).

Nappies were stored in plastic bags at room temperature until completion of the 24 -h collection period and then stored at $-20^{\circ} \mathrm{C}$. The 24 -h urine was extracted using established methods, with recovery of steroid hormones similar to those previously tested (26). To extract urine, nappies were defrosted, folded inside out, and placed in a plastic bag before extraction using a specially constructed hydraulic press. The extracted urine for the 24 -h collection was pooled and centrifuged. The collected specimens were stored at $-80{ }^{\circ} \mathrm{C}$ prior to GC-MS analysis.

\section{Assessment of urinary steroid hormones by GC-MS}

Steroid hormone measurement by GC-MS was performed on a Hewlett-Packard gas chromatograph 6890 (HewlettPackard) with mass selective detector 5973 by selective ion monitoring, as described earlier (28). This method enabled the following metabolites to be determined: tetrahydro-deoxycortisol (THS), cortisol (F), cortisone (E), tetrahydro-F (THF), $5 \alpha$-THF ( $5 \alpha \mathrm{THF})$, tetrahydro-E (THE), tetrahydro-corticosterone (THB), $5 \alpha$-Tetrahydro-corticosterone ( $5 \alpha$-THB), TH-dehydro-B (THA) and pregnandiol. Total $\mathrm{F}$ metabolites were calculated as the sum of the cortisol and cortisone metabolites. Steroid hormone concentrations are provided as $\mu \mathrm{g} / 24 \mathrm{~h}$.

By convention, enzyme activities are calculated by ratios of various metabolites (29). The enzyme activities described are therefore apparent activities and not directly measured. The apparent activity of $17 \alpha$-hydroxylase was calculated as the ratio of (THA $+\mathrm{THB}+5 \alpha \mathrm{THB}) /(\mathrm{THE}+$ $\mathrm{THF}+5 \alpha \mathrm{THF})$ and the apparent $11 \beta$-hydroxylase activity as 100xTHS/(THE + THF $+5 \alpha \mathrm{THF})$. For these apparent activities, high ratios represent low enzyme activities and vice versa.
$11 \beta$-hydroxysteroid dehydrogenase exists in two

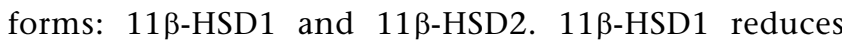
cortisol to the less active cortisone; the reverse reaction is also possible. Conversely, $11 \beta-\mathrm{HSD} 2$ irreversibly reduces cortisol to cortisone. The net cortisol to cortisone balance in response to a given total $11 \beta$-hydroxysteroid dehydrogenase enzymatic activity was assessed by calculation of the ratio of $\mathrm{F} / \mathrm{E}$ and the corresponding ratio of their $\mathrm{TH}$ metabolites $(\mathrm{THF}+5 \alpha \mathrm{THF}) / \mathrm{THE}(30)$.

\section{Statistical analyses}

Data are summarised as mean \pm s.D. or median (IQR) as appropriate for the distribution. Correlations between gestational age and steroid hormone excretion or enzyme activity were assessed using Spearman's correlation analysis for normotensive and pre-eclamptic groups separately and/or combined. Mann-Whitney $U$ test was used to analyse the subgroups, as appropriate according to standard normality testing. Unpaired student's $t$-test was used to compare normotensive and pre-eclamptic groups if standard normal distribution was confirmed. All the statistical analyses were performed using SYSTAT version 11 (SYSTAT Software, Inc., Erkrath, Germany). Significance was assigned at $P<0.05$.

\section{Results}

\section{Clinical characteristics}

We recruited 95 infants at 3 months and 45 infants at 12 months, all from singleton pregnancies. A summary of basic demographic data are given in Table 1. It can be seen that gestation ages were comparable at both time intervals.

\section{Cortisol metabolism at 3 and 12 months, related to gestational week at delivery in infants born to normotensive or pre-eclamptic mothers}

As can be seen from Fig. 2, there was still a residual effect of gestational age at delivery in relation to THS, THF and total $\mathrm{F}$ metabolites $(P<0.05)$, excretion being greater as gestation progressed. This relationship was lost at 12 months (Supplementary Figure 1, see section on supplementary data given at the end of this article). Figure 2 also shows summary data for cortisol and the various metabolites in the normotensive and pre-eclamptic groups. There was no difference in any of the measurements of the adrenal cortisol axis. By the 12 month visit,

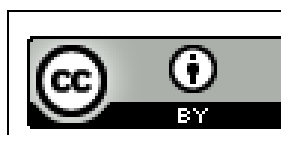

This work is licensed under a Creative Commons Attribution 3.0 Unported License. 


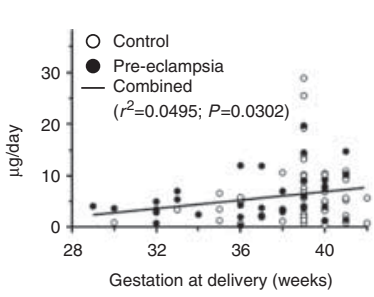

E
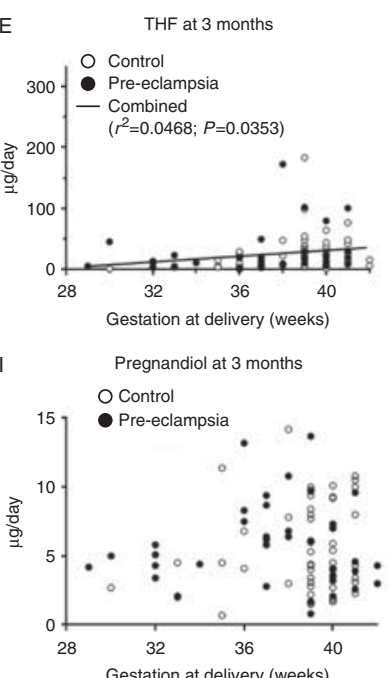

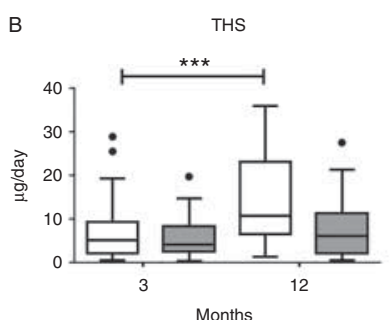

$\mathrm{F}$

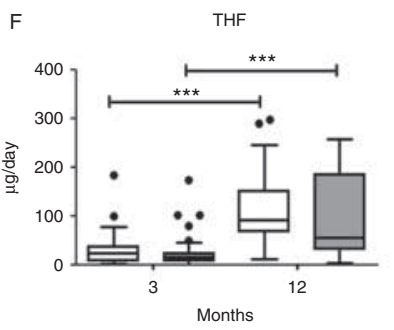

Pregnandiol

$\mathrm{J}$

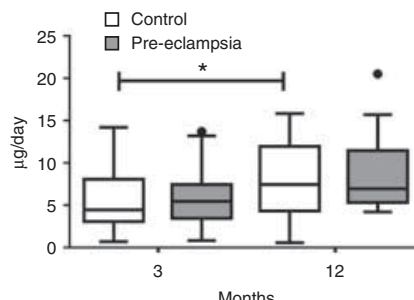

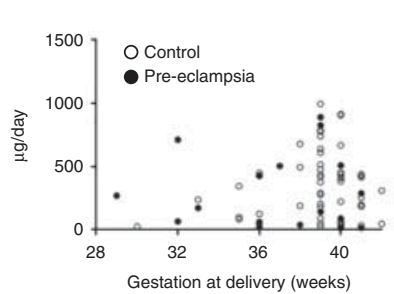

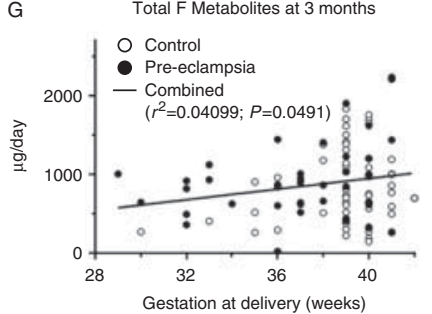

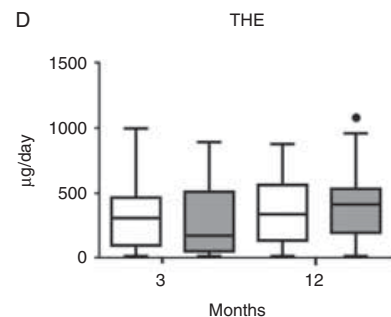

$\mathrm{H}$
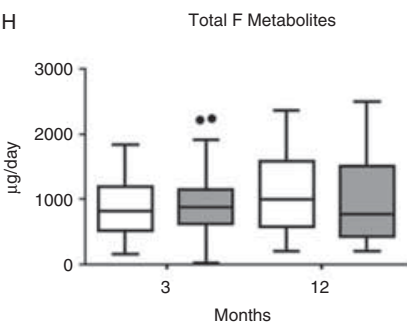

\section{Figure 2}

Cortisol metabolites at 3 and 12 months after birth in infants born to normotensive ( 3 months: $n=50$; 12 months: $n=29$; $\bigcirc$ or white bars) or pre-eclamptic ( 3 months: $n=50 ; 12$ months: $n=16$; 0 or grey bars) pregnancies, related to gestational week in infants. At 3 months, positive associations were observed for (A) THS $(r=0.2225, P=0.0302)$, (E) THF

excretion of THS and THF had risen significantly in the normotensive group $(P<0.05$ for both). THF had also risen in the pre-eclamptic group $(P<0.05)$. No difference was observed either with respect to timing of the visit or with respect to hypertensive status for $\mathrm{F}$, THE or total $\mathrm{F}$ metabolites $(P>0.1$ for all).

Pregnandiol excretion did not differ significantly at either 3 or 12 months between normotensive and preeclamptic groups. Both groups showed a rise in pregnandiol excretion between 3 and 12 months, which was significant only in the normotensive group $(P<0.05)$.

\section{Apparent enzyme activities relevant to cortisol metabolism at 3 and 12 months, related to gestational week in infants born to normotensive or pre-eclamptic pregnancies}

Figure 3A displays cortisol substrate delivery, B substrate production, and $\mathrm{C}$ and $\mathrm{D}$ cortisol degradation.

http://www.endocrineconnections.org
$\begin{array}{ll}\text { DOI: } 10.1530 / \text { EC-15-0084 } 2015 \text { The authors } \\ \text { Published by Bioscientifica Ltd. }\end{array}$

$(r=0.2163, P=0.0353)$ and (G) Total $\mathrm{F}(r=0.2022, P=0.0491)$ in the data overall. Specific metabolites include ( $A$ and $B$ ) tetrahydro (TH)-metabolite of deoxycortisol (S) (THS). (C and D) tetrahydro-E (THE); ( $E$ and F) TH-cortisol (THF); (G and H) Total F metabolites and (I and J) Pregnandiol. Data presented as median (IQR); ${ }^{*} P<0.05 ; * * * P<0.001$

Figure $3 \mathrm{C}$ and $\mathrm{D}$ shows that regardless of the putative primary site of cortisol degradation (hepatic or renal), there was still a significant residual effect of gestational age at delivery. This did not differ between normotensive and pre-eclamptic groups. It should be remembered that high ratios represent low activities.

Figure $3 \mathrm{~A}$ and $\mathrm{B}$ shows that at 3 months, gestational age at delivery was not associated with either $17 \alpha$ hydroxylase or $11 \beta$-hydroxylase activity. No association between gestational age and apparent $17 \alpha$-hydroxylase or $11 \beta$-hydroxylase activity was observed at 12 months in infants born either from normotensive or pre-eclamptic pregnancies (Supplementary Figure 1, see section on supplementary data given at the end of this article).

Figure $3 \mathrm{E}$ and $\mathrm{G}$ show the metabolite ratios, at 3 months, were significantly lower in the pre-eclamptic compared to normontensive controls, indicative of higher $17 \alpha$-hydroxylase and $11 \beta$-HSD activities of tetrahydrometabolites.

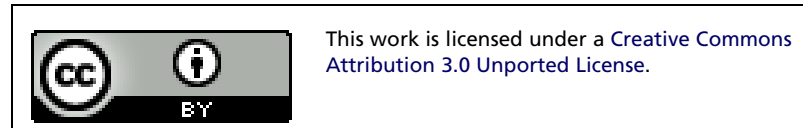


A

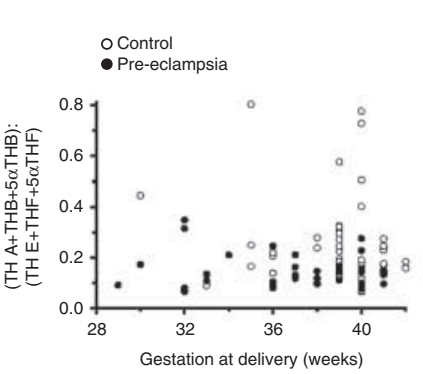

B

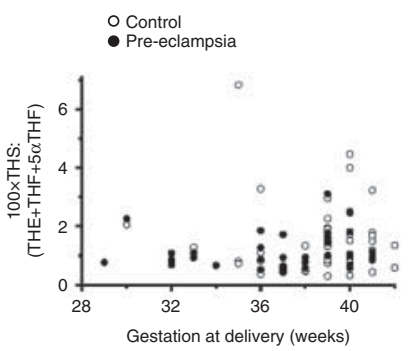

E

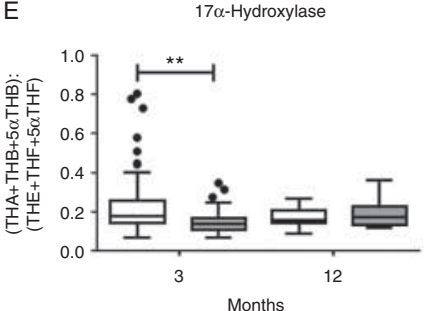

F

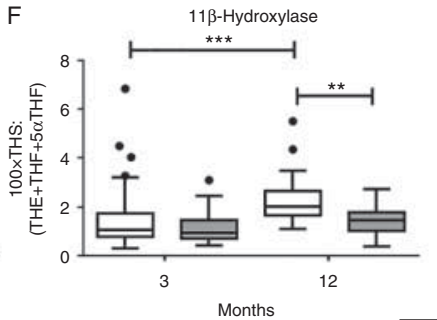

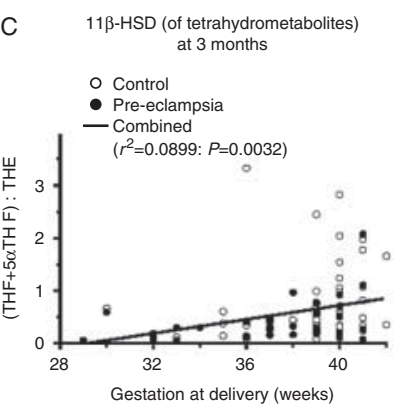

D

$11 \beta-H S D$ at 3 months

(20)

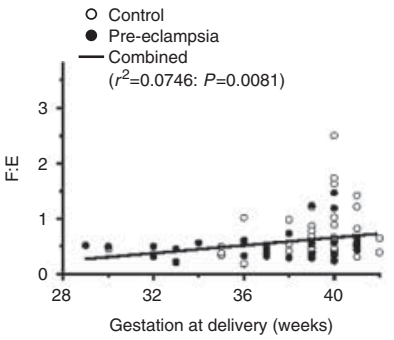

G $\quad 11 \beta-H S D$ (of tetrahydrometabolites)

H 11ß-HSD (Renal)

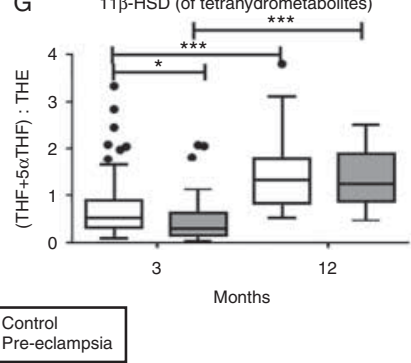

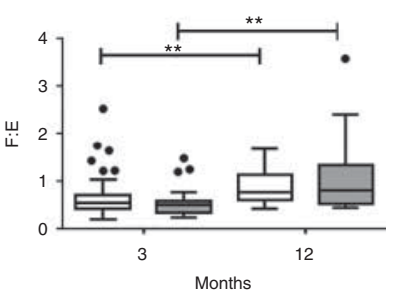

\section{Figure 3}

Urine apparent enzyme activities at 3 and 12 months after birth in infants born to normotensive ( 3 months: $n=50 ; 12$ months: $n=29$; $\bigcirc$ or white bars) or pre-eclamptic ( 3 months: $n=45 ; 12$ months: $n=16$; 0 or grey bars) pregnancies, related to gestational weeks in infants. At 3 months, positive associations were observed for both apparent measure of (C) 11- $\beta$-HSD, (of tetrahydrometabolites: $r=0.2998, P=0.0032$ ) and (D) (renal: $r=0.273$,
$P=0.0081)$ in the data overall. Specific metabolites include ( $A$ and $E$ ) $17 \alpha$ - Hydroxylase (B and F) 11 $\beta$-Hydroxylase; ( $C$ and D) 11- $\beta$-HSD (of tetrahydrometabolites) and (D and H) 11- $\beta$-HSD (renal). Low ratios indicate high apparent activities, whereas high ratios signify low conversion from substrate to the product. Data presented as median (IQR0); ${ }^{\star} P<0.05$; $* * P<0.01 ; * * * P<0.001$.
The significant increases in the metabolite ratios between 3 and 12 months were indicative of lower activities of all enzymes except $17 \alpha$-hydroxylase activities in the normotensive group (Fig. 3F, G and H). A similar pattern was only seen in the pre-eclamptic group for the two ratios indicative of $11 \beta$-HSD activities (Fig. 3G and H). Thus, there was a significant difference

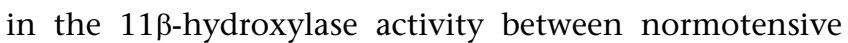
and pre-eclamptic groups at 12 months, which was not present at 3 months (Fig. 3F).

\section{Discussion}

This is one of the first studies of urinary cortisol metabolites in infants through the first year of life using highly sensitive and specific mass spectrometry-based methodology. It provides data regarding infants exposed to a pre-eclamptic or normotensive pregnancy. In this analysis, the urinary excretion of individual cortisol metabolites and combined cortisol metabolites at 3 months postnatally, still shows an effect of gestational age at delivery in both groups. This highlights the importance of taking into consideration gestational age at delivery in the interpretation of steroid excretion, over at least the first 3 months of postnatal life. The fetal adrenal undergoes a maturational spurt between 32 and 34 weeks (31), considered to be preparing the fetus for birth, as it is followed by the rapid maturation of a variety of other hormone systems. Infants in our study born before this time will not have been exposed to this, which may be associated with compromised adrenal maturation.

The excretion of THS represents substrate availability: in the normotensive group this rises between 3 and 12 months postnatally. THF also rises in parallel to this, although 11ß-hydroxylase activity has fallen in this group, the substrate availability more than compensates. THF also rises between 3 and 12 months in the pre-eclamptic group, despite both substrate availability and $11 \beta$-hydroxylase activity remaining almost constant over this time. However, the significant fall in both forms of $11 \beta$-HSD activity, may have enabled this rise in THF. The increased apparent $11 \beta$-hydroxylase activity in the pre-eclamptic group by comparison to the normotensive group at 12 months is in line with the observed maintained F, THF and total F 
excretion, despite the lower THS excretion. The lack of increase over time of pregnandiol in the pre-eclamptic group implies a lower substrate delivery.

In normotensive pregnancies, the increase in precursors and production of cortisol is to be expected as the adrenal cortex develops from the fetal to the definitive fasciculate zone (18) as can be seen Fig. 2 in response to gestational age at delivery.

Reduced placental 11 $\beta$-HSD activity, which has been described before (32) does not translate into reduced systemic apparent $11 \beta$-HSD activity during the first year of life. Whereas we identified significant falls in both forms of $11 \beta$-HSD activity in infants of both normotensive and pre-eclamptic pregnancies during the first postnatal year, Planck et al. investigating SGA infants aged between 2 and 13 years, could no longer identify major changes in enzyme activities (33). Likewise, our previous data on high placental cortisol availability in preterm gestation (34) are not reflected in the cortisol production during the first 12 months after birth, but could be a stimulus for the high fetal 11 $\beta$-HSD activity, which we found at 3 months. Of interest, the reduced ACTH-induced stimulation of cortisol release in preterm infants (35) was not reflected by baseline cortisol production in our study.

Despite a rich literature on HPA maturation in conditions such as intrauterine hypoxia with an excess of cortisol (36), little information is available concerning cortisol metabolites in the infants from pre-eclamptic mothers. Our findings suggest that the steroid hormone metabolism of preeclampsia does not reflect the profile seen in hypoxia. The compromised upregulation of the cortisol precursor, deoxycortisol could be due to the availability of the major steroid hormone precursor cholesterol, or its transport, might be affected due to preeclamptic intrauterine conditions and placental dysfunction. This assumption is supported by a smaller increase in pregnandiol in the pre-eclamptic group. Though the data in early childhood are not available, data at birth indicate reduced delivery of cholesterol to the fetus in IUGR and pre-eclampsia $(37,38,39)$. The potentially compromised cholesterol transport due to fetal programming may potentially contribute to later life vascular disease and atherosclerosis in these infants (40).

As previously mentioned, by 3 months there was a substantial dropout in attendance at the research unit, which was exacerbated by 12 months. One of us (CR), attempted to contact women at their homes, but there were numerous logistical issues; part of these related to collection of nappies. An additional limitation lay in the use of pure cellulose nappies because of their reduced capacity to absorb urine, thus complete 24-h collection may not have been achieved. Incomplete voiding in these very young infants might have led to limited comprehensive or incomplete urine sampling. This limitation only affects total steroid hormone amounts and not the ratios derived. As muscle mass will be different in preterm and term infants (41) and stability of creatinine was not tested thoroughly for the nappies used at initial study entry, we only provide absolute daily excretion of steroid hormones. We could not control for a limited nappy volume, which might be overwhelmed by strong voiding.

In conclusion, in infants born from pre-eclamptic mothers, cortisol excretion is determined by an increase in 11ß-hydroxylase, which compensates for the high $11 \beta$-HSD-dependent cortisol degradation at 3 months. This might still be present, after protecting the fetus from high placental cortisol leakage during pre-eclamptic conditions (34). The elevated apparent $11 \beta$-hydroxylase at 12 months appears to counterbalance the reduced substrate availability resulting in an unaltered total cortisol metabolite excretion. Future research should be directed to understand the role and development of salvage mechanisms, such as reverse cholesterol transport by enzymes such as the $27 \alpha$-hydroxylase.

\section{Supplementary data}

This is linked to the online version of the paper at http://dx.doi.org/10.1530/ EC-15-0084.

\section{Declaration of interest}

The authors declare that there is no conflict of interest that could be perceived as prejudicing the impartiality of the research reported.

\section{Funding}

H D Mistry is supported by an ERA-EDTA Fellowship (ERA LTF 137-2013). M G Mohaupt is supported by the Swiss National Foundation (personal grants 3200B0-113902/1, 32-135596).

\section{Author contribution statement}

H D Mistry, C Roy, L O Kurlak, B Dick and R Chikhi performed the experiments and analyses and drafted the paper. $\mathrm{F}$ Broughton Pipkin and $\mathrm{M}$ $G$ Mohaupt initiated and guided the research and corrected drafts of the paper. J Waugh reviewed the research and analyses and reviewed the writing of the paper.

\section{Acknowledgements}

We thank the mothers and their infants for carefully collecting the nappies and coming back for the visits. Many thanks also to the midwives for consenting, as well as sample and data collection. 


\section{References}

1 Brooks AN, Hagan DM \& Howe DC. Neuroendocrine regulation of pituitary-adrenal function during fetal life. European Journal of Endocrinology 1996135 153-165. (doi:10.1530/eje.0.1350153)

2 Rainey WE, Rehman KS \& Carr BR. Fetal and maternal adrenals in human pregnancy. Obstetrics and Gynecology Clinics of North America 200431 817-835. (doi:10.1016/j.ogc.2004.08.006)

3 Liggins GC. The role of cortisol in preparing the fetus for birth. Reproduction, Fertility, and Development 19946 141-150. (doi:10.1071/ RD9940141)

4 Liggins GC. Adrenocortical-related maturational events in the fetus. American Journal of Obstetrics and Gynecology 1976126 931-941.

5 Steegers EA, von Dadelszen P, Duvekot JJ \& Pijnenborg R. Pre-eclampsia. Lancet 2010376 631-644. (doi:10.1016/S01406736(10)60279-6)

6 Broughton Pipkin F. Risk factors for preeclampsia. New England Journal of Medicine 2001344 925-926. (doi:10.1056/ NEJM200103223441209)

7 Roberts JM \& Lain KY. Recent insights into the pathogenesis of preeclampsia. Placenta 200223 359-372. (doi:10.1053/plac.2002.0819)

8 Abitbol CL \& Rodriguez MM. The long-term renal and cardiovascular consequences of prematurity. Nature Reviews. Nephrology 20128 265-274. (doi:10.1038/nrneph.2012.38)

9 Bertram CE \& Hanson MA. Prenatal programming of postnatal endocrine responses by glucocorticoids. Reproduction 2002124 459-467. (doi:10.1530/rep.0.1240459)

10 Benediktsson R, Lindsay RS, Noble J, Seckl JR \& Edwards CR. Glucocorticoid exposure in utero: new model for adult hypertension. Lancet 1993341 339-341. (doi:10.1016/0140-6736(93)90138-7)

11 Dodic M, Peers A, Coghlan JP \& Wintour M. Can excess glucocorticoid, predispose to cardiovascular and metabolic disease in middle age? Trends in Endocrinology and Metabolism 199910 86-91. (doi:10.1016/ S1043-2760(98)00125-8)

12 Schoof E, Girstl M, Frobenius W, Kirschbaum M, Dorr HG, Rascher W \& Dotsch J. Decreased gene expression of $11 \beta$-hydroxysteroid dehydrogenase type 2 and 15-hydroxyprostaglandin dehydrogenase in human placenta of patients with preeclampsia. Journal of Clinical Endocrinology and Metabolism 200186 1313-1317. (doi:10.1210/jcem.86.3.7311)

13 Gardner DS, Fletcher AJ, Fowden AL \& Giussani DA. Plasma adrenocorticotropin and cortisol concentrations during acute hypoxemia after a reversible period of adverse intrauterine conditions in the ovine fetus during late gestation. Endocrinology 2001142 589-598. (doi:10.1210/endo.142.2.7980)

14 Heiniger CD, Kostadinova RM, Rochat MK, Serra A, Ferrari P, Dick B, Frey BM \& Frey FJ. Hypoxia causes down-regulation of 11ß-hydroxysteroid dehydrogenase type 2 by induction of Egr-1. FASEB Journal 2003 17 917-919. (doi:10.1096/fj.02-0582fje)

15 Seckl JR, Cleasby M \& Nyirenda MJ. Glucocorticoids, 11ß-hydroxysteroid dehydrogenase, and fetal programming. Kidney International 200057 1412-1417. (doi:10.1046/j.1523-1755.2000.00984.x)

16 Roberts D \& Dalziel S. Antenatal corticosteroids for accelerating fetal lung maturation for women at risk of preterm birth. Cochrane Database of Systematic Reviews 2006 CD004454. (doi:10.1002/14651858. CD004454.pub2)

17 Heckmann M, Hartmann MF, Kampschulte B, Gack H, Bodeker RH, Gortner L \& Wudy SA. Cortisol production rates in preterm infants in relation to growth and illness: a noninvasive prospective study using gas chromatography-mass spectrometry. Journal of Clinical Endocrinology and Metabolism 200590 5737-5742. (doi:10.1210/jc.2005-0870)

18 Bolt RJ, van Weissenbruch MM, Cranendonk A, Lafeber HN \& Delemarre-Van De Waal HA. The corticotrophin-releasing hormone test in preterm infants. Clinical Endocrinology 200256 207-213. (doi:10.1046/j.0300-0664.2001.01467.x)

19 Bolt RJ, Van Weissenbruch MM, Popp-Snijders C, Sweep FG, Lafeber HN $\&$ Delemarre-van de Waal HA. Maturity of the adrenal cortex in very preterm infants is related to gestational age. Pediatric Research 200252 405-410. (doi:10.1203/00006450-200209000-00017)

20 Bagnoli F, Mori A, Fommei C, Coriolani G, Badii S \& Tomasini B. ACTH and cortisol cord plasma concentrations in preterm and term infants. Journal of Perinatology 201333 520-524. (doi:10.1038/jp.2012.165)

21 Krishnaveni GV, Veena SR, Dhube A, Karat SC, Phillips DI \& Fall CH. Size at birth, morning cortisol and cardiometabolic risk markers in healthy Indian children. Clinical Endocrinology 201480 73-79. (doi:10. 1111/cen.12143)

22 Raff H, Auchus RJ, Findling JW \& Nieman LK. Urine free cortisol in the diagnosis of Cushing's syndrome: is it worth doing and, if so, how? Journal of Clinical Endocrinology and Metabolism 2015100 395-397. (doi:10.1210/jc.2014-3766)

23 Zumoff B, Fukushima DK \& Hellman L. Intercomparison of four methods for measuring cortisol production. Journal of Clinical Endocrinology and Metabolism 197438 169-175. (doi:10.1210/jcem-382-169)

24 Brown MA, Lindheimer MD, de Swiet M, Van Assche A \& Moutquin JM. The classification and diagnosis of the hypertensive disorders of pregnancy: statement from the International Society for the Study of Hypertension in Pregnancy (ISSHP). Hypertension in Pregnancy 200120 IX-XIV. (doi:10.3109/10641950109152635)

25 Gardosi J, Francis A Customised Centile Calculator 2006 www.gestation.net.

26 Heckmann M, Hartmann MF, Kampschulte B, Gack H, Bodeker RH, Gortner L \& Wudy SA. Assessing cortisol production in preterm infants: do not dispose of the nappies. Pediatric Research 200557 412-418. (doi:10.1203/01.PDR.0000153947.51642.C1)

27 Roberts SB \& Lucas A. Measurement of urinary constituents and output using disposable napkins. Archives of Disease in Childhood $1985 \mathbf{6 0}$ 1021-1024. (doi:10.1136/adc.60.11.1021)

28 Quattropani C, Vogt B, Odermatt A, Dick B, Frey BM \& Frey FJ. Reduced activity of $11 \beta$-hydroxysteroid dehydrogenase in patients with cholestasis. Journal of Clinical Endocrinology 2001108 1299-1305. (doi:10.1172/JCI12745)

29 Henschkowski J, Stuck AE, Frey BM, Gillmann G, Dick B, Frey FJ \& Mohaupt MG. Age-dependent decrease in 11 $\beta$-hydroxysteroid dehydrogenase type $2(11 \beta$-HSD2) activity in hypertensive patients. American Journal of Hypertension 200821 644-649. (doi:10.1038/ajh. 2008.152)

30 Arampatzis S, Pasch A, Lippuner K \& Mohaupt M. Primary male osteoporosis is associated with enhanced glucocorticoid availability. Rheumatology 201352 1983-1991. (doi:10.1093/rheumatology/ ket228)

31 Person Murphy BE, Laplante Branchaud C The Fetal Adrenal. In Maternal-Fetal Endocrinology Eds D Tulchinsky, A Brian Little. London: W.B. Saunders Company, 1994.

32 Kajantie E, Dunkel L, Turpeinen U, Stenman UH, Wood PJ, Nuutila M \& Andersson S. Placental $11 \beta$-hydroxysteroid dehydrogenase- 2 and fetal cortisol/cortisone shuttle in small preterm infants. Journal of Clinical Endocrinology and Metabolism 200388 493-500. (doi:10.1210/jc.2002021378)

33 Plank C, Meissner U, Rauh M, Wollmann H, Dorr HG, Rascher W \& Dotsch J. Cortisol-cortisone ratios in small for gestational age (SGA) children without postnatal catch-up growth. Clinical Endocrinology 200767 304-309. (doi:10.1111/j.1365-2265.2007.02884.x)

34 Aufdenblatten M, Baumann M, Raio L, Dick B, Frey BM, Schneider H, Surbek D, Hocher B \& Mohaupt MG. Prematurity is related to high placental cortisol in preeclampsia. Pediatric Research 200965 198-202. (doi:10.1203/PDR.0b013e31818d6c24)

35 Bolt RJ, van Weissenbruch MM, Popp-Snijders C, Sweep CG, Lafeber HN \& Delemarre-van de Waal HA. Fetal growth and the function of the adrenal cortex in preterm infants. Journal of Clinical Endocrinology and Metabolism 200287 1194-1199. (doi:10.1210/jcem. 87.3.8295)

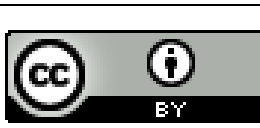

This work is licensed under a Creative Commons Attribution 3.0 Unported License. 
36 Braems G. Fetal hypoxemia on a molecular level: adaptive changes in the hypothalamic-pituitary-adrenal (HPA) axis and the lungs. European Journal of Obstetrics, Gynecology, and Reproductive Biology 2003110 (Suppl 1) S63-S69. (doi:10.1016/S0301-2115(03)00174-X)

37 Hentschke MR, Poli-de-Figueiredo CE, Pinheiro da Costa BE, Kurlak LO, Williams PJ \& Mistry HD. Is the atherosclerotic phenotype of preeclamptic placentas due to altered lipoprotein concentrations and placental lipoprotein receptors? Role of a small-for-gestational-age phenotype. Journal of Lipid Research 201354 2658-2664. (doi:10.1194/ jlr.M036699)

38 Pecks U, Brieger M, Schiessl B, Bauerschlag DO, Piroth D, Bruno B, Fitzner C, Orlikowsky T, Maass N \& Rath W. Maternal and fetal cord blood lipids in intrauterine growth restriction. Journal of Perinatal Medicine 201240 287-296. (doi:10.1515/jpm.2011.135)
39 Pecks U, Caspers R, Schiessl B, Bauerschlag D, Piroth D, Maass N \& Rath $\mathrm{W}$. The evaluation of the oxidative state of low-density lipoproteins in intrauterine growth restriction and preeclampsia. Hypertension in Pregnancy 201231 156-165. (doi:10.3109/10641955. 2010.544805)

40 Fang L, Choi SH, Baek JS, Liu C, Almazan F, Ulrich F, Wiesner P, Taleb A, Deer E, Pattison J et al. Control of angiogenesis by AIBP-mediated cholesterol efflux. Nature 2013498 118-122. (doi:10.1038/ nature12166)

41 Ahmad I, Nemet D, Eliakim A, Koeppel R, Grochow D, Coussens M, Gallitto S, Rich J, Pontello A, Leu SY et al. Body composition and its components in preterm and term newborns: a cross-sectional, multimodal investigation. American Journal of Human Biology 201022 69-75. (doi:10.1002/ajhb.20955)

Received in final form 26 August 2015

Accepted 16 September 2015
This work is licensed under a Creative Commons Attribution 3.0 Unported License. 